\title{
Development of CALPHAD database for both Ti- and TiAl- based alloys
}

\author{
Yang Yang* , Hai-Lin Chen, Qing Chen, Anders Engström \\ Thermo-Calc Software AB, Råsundavägen 18, 16967 Solna, Sweden \\ *E-mail: yang@thermocalc.com
}

\begin{abstract}
Phase diagram calculations and phase transformation simulations have been widely employed to materials design and process optimization. Recent development of a 27-element thermodynamic database (TCTI2) together with a compatible mobility database (MOBTI3) for Tiand TiAl-based alloys is reported. The TCTI2 database has been developed in a systematic way in order to cope with the complexity in phase relations and phase transformations in both conventional Ti-based and newly emerging TiAl-based alloys. It can be used with Thermo-Calc and the add-on Diffusion Module (DICTRA) and Precipitation Module (TC-PRISMA) for calculations of multi-component alloys. Feasible calculations are ranging from the traditional stable and metastable phase equilibria ( $\beta$-transus temperature, evolution of phase fractions $v$ s. temperature, martensitic temperature, etc.) to some thermophysical properties (density, thermal expansion, etc.). Using a combination of TCTI2 and MOBTI3, one can simulate diffusion-controlled phase transformation and precipitation kinetics. The intermetallic TiAl-based alloys are known for their own complexities and the present modeling for $\alpha_{2}-\mathrm{Ti}_{3} \mathrm{Al}$ and $\gamma$-TiAl based alloys will be discussed. Typical calculated examples for various properties in titanium alloys are presented with the emphasis on validation against experimental observations in multi-component commercial alloys. This database is expected to efficiently support further development of Ti- and TiAl-based alloys, as well as to promote process simulations with accurate prerequisites.
\end{abstract}

Keywords: CALPHAD, multicomponent simulation, Ti-alloys, Titanium aluminides

\section{Introduction}


Titanium alloys have been widely applied in aerospace, biomedical and chemical industries due to their exceptional strength-to-weight ratio, excellent corrosion resistance and good biological compatibility [1-3]. Conventional titanium alloys are usually classified into $\alpha, \alpha+\beta$, and $\beta$ alloys, with further subdivision into near- $\alpha$ and near- $\beta$ alloys [2]. The subclasses, near- $\alpha$ and near- $\beta$, refer to alloys whose compositions place them near the $\alpha /(\alpha+\beta)$ or $(\alpha+\beta) / \beta$ phase boundaries, respectively. The microstructure of conventional titanium alloys and their properties strongly depend on the alloy's composition [2].

Titanium aluminide (TiAl) based alloys represent a new class of engineering lightweight structural materials, which become promissing candidates for aerospace and automotive applications [4-6]. TiAl-based alloys exhibit superior specific strength-temperature properties compared with steels, $\mathrm{Ni}$-based superalloys and conventional titanium alloys particularly in the temperature range of 600 to $800{ }^{\circ} \mathrm{C}$ [7]. The phase constituents of TiAl-based alloys are highly susceptible to small changes in the alloy's chemistry and heat treatment procedure $[8,9]$.

One essential research interest in titanium alloys goes to investigate phase equilibria, transformation and microstructure evolution. The traditional experimental approach can be onerous and expensive even for a binary system and furthermore the required amount of experimental work rises sharply for a multicomponent alloy. To accelerate the understanding and design of titanium alloys, CALPHAD (CALculation of PHAse Diagrams) is emerging as a key approach. CALPHAD-type simulations have been successfully employed for alloy design and process optimization for more than 20 years [10-15].

The quality of CALPHAD simulations entirely depends on the accuracy of the database and the versatility of the software. Therefore, TCTI2 [16] has been developed in a 27-element framework with 269 binary systems and 95 ternary systems assessed. This thermodynamic database includes all stable phases and most important metastable phases that may form in titanium alloys. The database can also be used for predicting solidification behavior of alloys with the SCHEIL_GULLIVER module in Thermo-Calc. The compatible kinetic database MOBTI3 [17] can be used together with TCTI2 to study different diffusion-controlled phenomena in titanium alloys, such as e.g. microsegregation during solidification, homogenization kinetics, growth/dissolution 
kinetics of precipitates, by using the Diffusion Module (DICTRA). More details on the software package are available at www.thermocalc.com.

In this paper, the authors will introduce the TCTI2 database and present the major achievements in its development. This paper presents information on phase modeling and a database overview (Section 2), and demonstrates some applications of the database for titanium alloys (Section 3).

\section{Thermodynamic models and database overview}

\subsection{Database overview}

TCTI2 is developed in a 27-element framework: Ag, Al, B, C, Co, Cr, Fe, H, Hf, Mn, Mo, N, Nb, Ni, O, Pd, Pt, Re, Ru, Si, Sn, Ta, Ti, V, W, Y, Zr. In total, 269 binaries and 95 ternaries [16] have been assessed. An extensive investigation on crystallography of all solid phases has been performed in the present development and the phases having the same crystal structure were unified as one phase. A complete list of phases and models in TCTI2 can be found elsewhere [16].

All necessary volume data (including molar volume and thermal expansion) have been assessed with the implemented model $[18,19]$ for most solution phases and intermetallic phases in TCTI2. This enables one to calculate volume fraction of phases, density and thermal expansivity, as well as lattice parameters for cubic structures using Thermo-Calc.

\subsection{Thermodynamic models}

The thermodynamic database consists of descriptions of Gibbs energy for each phase. The key to develop a thermodynamic database is to optimize the model parameters in Gibbs energy expressions based on the available thermochemical data (enthalpy, entropy, heat capacity, activity, etc.) and phase equilibrium data (liquidus, solidus, phase boundary, etc.). All stable solid phases are modelled in each assessed binary and ternary system unless the equilibria associated with a phase are not known at all or its stability is questionable. Appropriate thermodynamic models are selected and used for different types of phases. 


\subsubsection{Solution phases}

Common solution phases are described with substitutional model. The molar Gibbs energy for solution phase $\Phi$ is described as a function of composition $\left(x_{i}\right)$ and temperature $(T)$ as:

$$
G_{m}^{\phi}=\sum_{i} x_{i}^{\circ} G_{i}+R T \sum_{i} x_{i} \ln x_{i}+{ }^{E} G_{m}^{\phi}
$$

where ${ }^{0} G_{i}$ is the molar Gibbs energy of a pure element (component) $i$, which is taken from the SGTE PURE 5 database [20]; $x_{i}$ is the concentration of element $i ; R$ is the gas constant; $T$ is the temperature. ${ }^{E} G_{m}^{\mathrm{T}}$ represents the excess Gibbs energy expressed by

$$
{ }^{E} G_{m}^{\phi}=\sum_{i} \sum_{j>i} x_{i} x_{j} L_{i j}+x_{i} x_{j} x_{k} I_{i, j, k}
$$

where $L_{i, j}$ and $I_{i, j, k}$ are the binary and ternary interaction parameters, respectively, between components $i, j$ and $k$ and may depend on temperature.

Associate model is used for the liquid phase in some systems and it's compatible with the substitutional model.

\subsubsection{Sublattice model}

The sublattice model is frequently used in CALPHAD modelling. The concept of 'sublattice' was introduced in CALPHAD to distinguish the sites and describe the site occupancies in a more physically sound way [11]. The basic premise for this model is that a sublattice is assigned for each distinct site in the crystal structure, which is known as Wyckoff sites. Models with two or more sublattices are referred to as sublattice models [21]. The number of sublattices for a solid phase depends on the crystallographic structure and compositional complexity. In actual thermodynamic assessment simplifications by merging several Wyckoff sites with similar occupancies as one sublattice are necessary to make a model applicable. 
In TCTI2, most sublattice models consist of only two sublattices (2SLs) or three sublattices (3SLs) in order to assure the efficiency in calculations. For a $2 \mathrm{SL}$ model $(\mathrm{A}, \mathrm{B}, \ldots)_{\mathrm{S} 1}(\mathrm{~A}, \mathrm{~B}, \ldots)_{\mathrm{S} 2}$ assuming that $m$ constituents are on the first sublattice and $n$ constituents on the second sublattice, the Gibbs energy can be described as:

$$
\begin{aligned}
& G^{\varphi}=\sum_{i=1}^{m} \sum_{j=1}^{n} y_{i}^{(1)} y_{j}^{(2)} G_{i j j}^{\varphi}+R T\left(S 1 \cdot \sum_{i}^{m} y_{i}^{(1)} \ln \left(y_{i}^{(1)}\right)+S 2 \cdot \sum_{i}^{n} y_{j}^{(2)} \ln \left(y_{j}^{(2)}\right)\right) \\
& +\sum_{i=1}^{m-1} \sum_{j=i+1}^{m} \sum_{k}^{n} y_{j}^{(1)} y_{j}^{(1)} y_{k}^{(2)} L_{i j / k}+\sum_{i=1}^{n-1} \sum_{j=i+1}^{n} \sum_{k}^{m} y_{k}^{(1)} y_{j}^{(2)} y_{j}^{(2)} L_{k-j j}+\sum_{i=1}^{m-1} \sum_{j=i+1}^{m} \sum_{k=1}^{n} \sum_{j=k+1}^{n-1} y_{j}^{(1)} y_{j}^{(1)} y_{k}^{(2)} y_{j}^{(2)} L_{j=k l}
\end{aligned}
$$

For instance, $\alpha_{2}$ phase $\left(\mathrm{AlTi}_{3} \mathrm{DO}_{19}\right), \gamma$ phase $\left(\mathrm{AlTi}_{-} \mathrm{L}_{0}\right)$ and $\omega_{0}-\mathrm{Ti}_{4} \mathrm{Al}_{3} \mathrm{Nb}$ phase $\left(\mathrm{B}_{2}{ }_{2}\right.$ omega $)$ are described with a 3SL model.

The ordered B2 phase is modeled with the so-called partitioned model in conjunction with its disordered counterpart, Bcc_A2. The elaboration on the partitioned model can be found elsewhere $[22,23]$.

\section{Applications}

This section will present some application examples. Simulations for phase formation under conditions deviating substantially from equilibrium can be further made by introducing kinetic modeling $[24,25]$.

The impurity level in alloys inevitably accounts for varying features such as $\beta$-transus temperature and volume fractions of $\alpha$ or $\beta$ vs. temperature. It's well known low levels of interstitial impurities, such as $\mathrm{O}$ and $\mathrm{N}$, can significantly modify phase equilibria in conventional Ti-alloys. For TiAl-based alloys, certain amount of $\mathrm{Nb}$ and $\mathrm{Mo}$ tend to impede diffusion processes. While this behavior can be exploited with regard to creep and thermal stability of the microstructure, kinetics of phase transformation and recrystallization process might be slowed down [26]. The deviation from equilibrium conditions can have significant impacts on evolution of phase fractions. 


\subsection{Phase equilibria in multi-component alloys}

Ti-6242Si with an outstanding combination of tensile strength, creep strength and toughness [27] is used primarily for compressor discs in gas turbines. The beta-approach curve (the evolution of beta-phase volume fraction with temperature) is calculated and presented in Fig. 1a. The calculated equilibrium compositions of $\mathrm{Al}$ and $\mathrm{Mo}$ in $\alpha$ and $\beta$ for the Ti-6242Si alloy are shown in Fig. $1 \mathrm{~b}$ together with experimental data from [28]. 

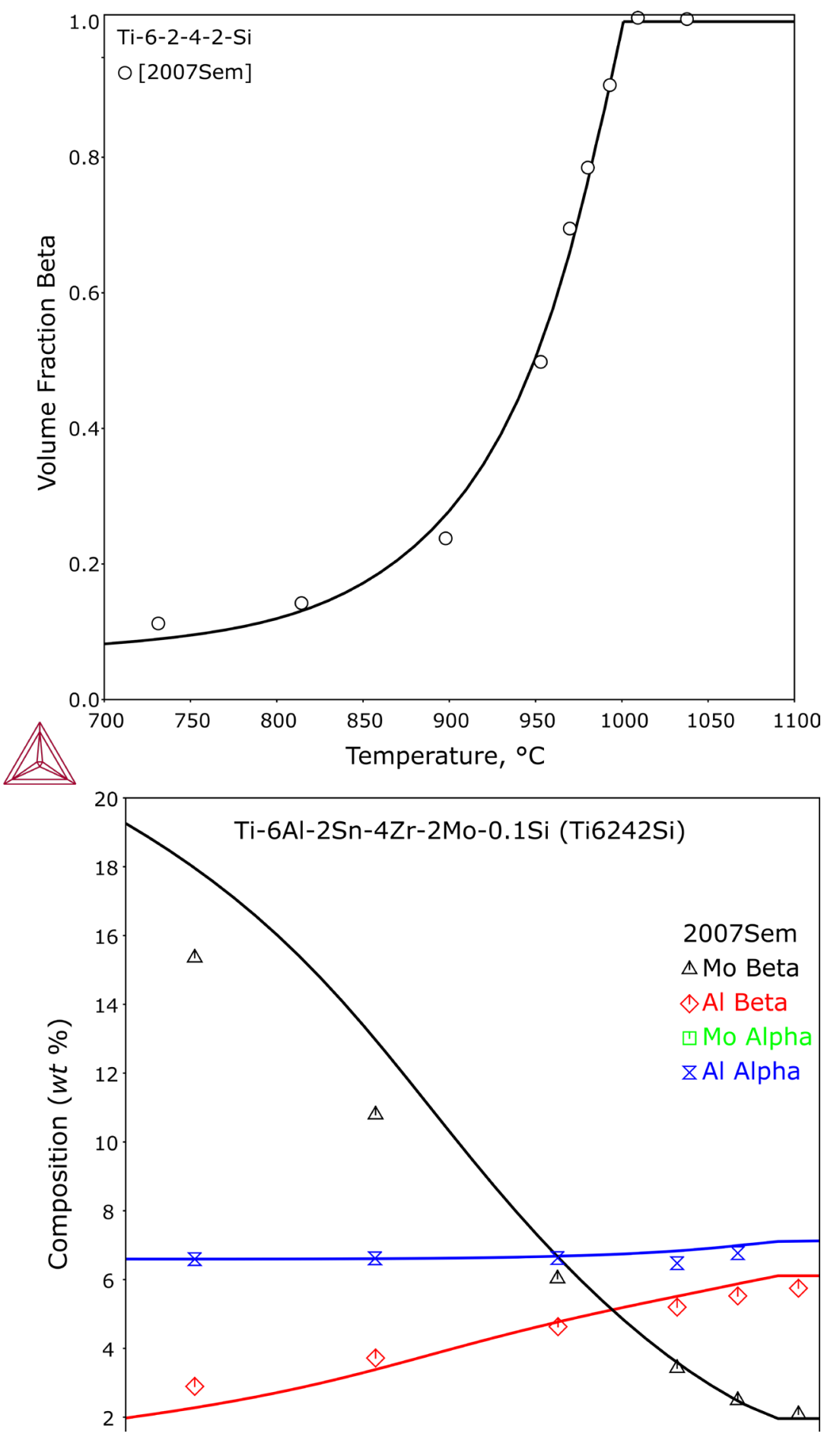


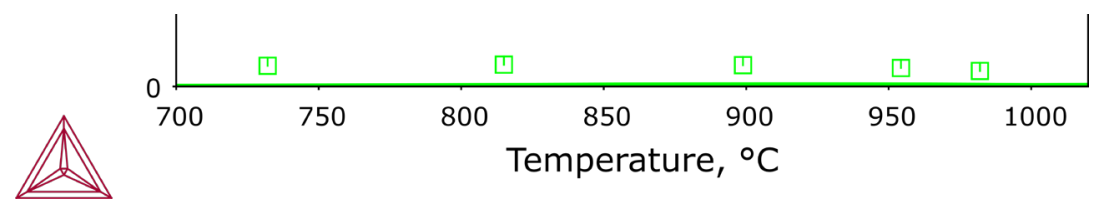

Fig. 1. Phase equilibria for Ti-6242Si alloy: (a) beta-approach curve and (b) variation of Al and Mo content in $\alpha$ and $\beta$ phases as a function of temperature.

Fig. 2 compares the calculated phase fractions for a typical TNM alloy from 600 to $1600{ }^{\circ} \mathrm{C}$ with experimental observations [26]. The amount of 0 is reasonably assumed as 1500 at. ppm here. The experimental data were obtained under conditions close to thermodynamic equilibrium by [26] concerning evolution of phase fractions, transition temperatures. Excellent predictions can be made for this alloy, particularly the $\gamma$-solvus temperature and the eutectoid temperature where the $\alpha \hookrightarrow \alpha_{2}$ order/disorder reaction occurs.

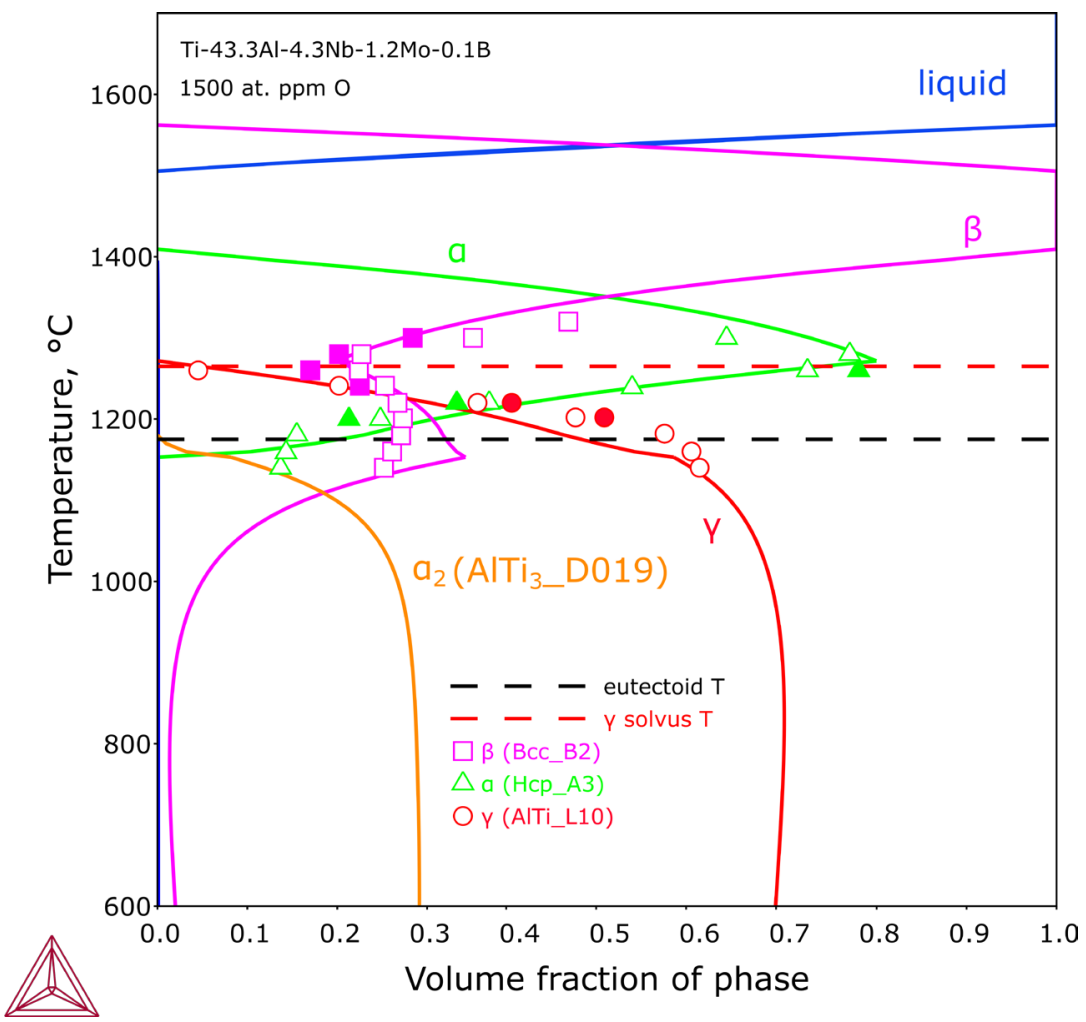


Fig. 2. Calculated phase fraction vs. temperature for Ti-43.3Al-4.3Nb-1.2Mo-0.1B alloy.

\section{$3.2 \beta$-transus Temperature}

Generally, the different microstructures of conventional Ti-alloys are obtained by various thermomechanical treatments. A central point for thermomechanical treatment is the $\beta$-transus temperature, $\mathrm{T}_{\beta}$, since it separates the single $\beta$ phase field from the two-phase $\alpha+\beta$ field [2]. Therefore, knowledge of $\mathrm{T}_{\beta}$ is of critical importance to alloy design. Fig. 3 shows a comparison between observed and predicted $\beta$-transus temperatures for a wide variety of commercial $\mathrm{Ti}^{-}$ alloys. The dashed lines indicate an uncertainty of $\pm 20^{\circ} \mathrm{C}$. The nominal composition for major elements and average value for impurities in the datasheet of respective alloy were used in calculations.

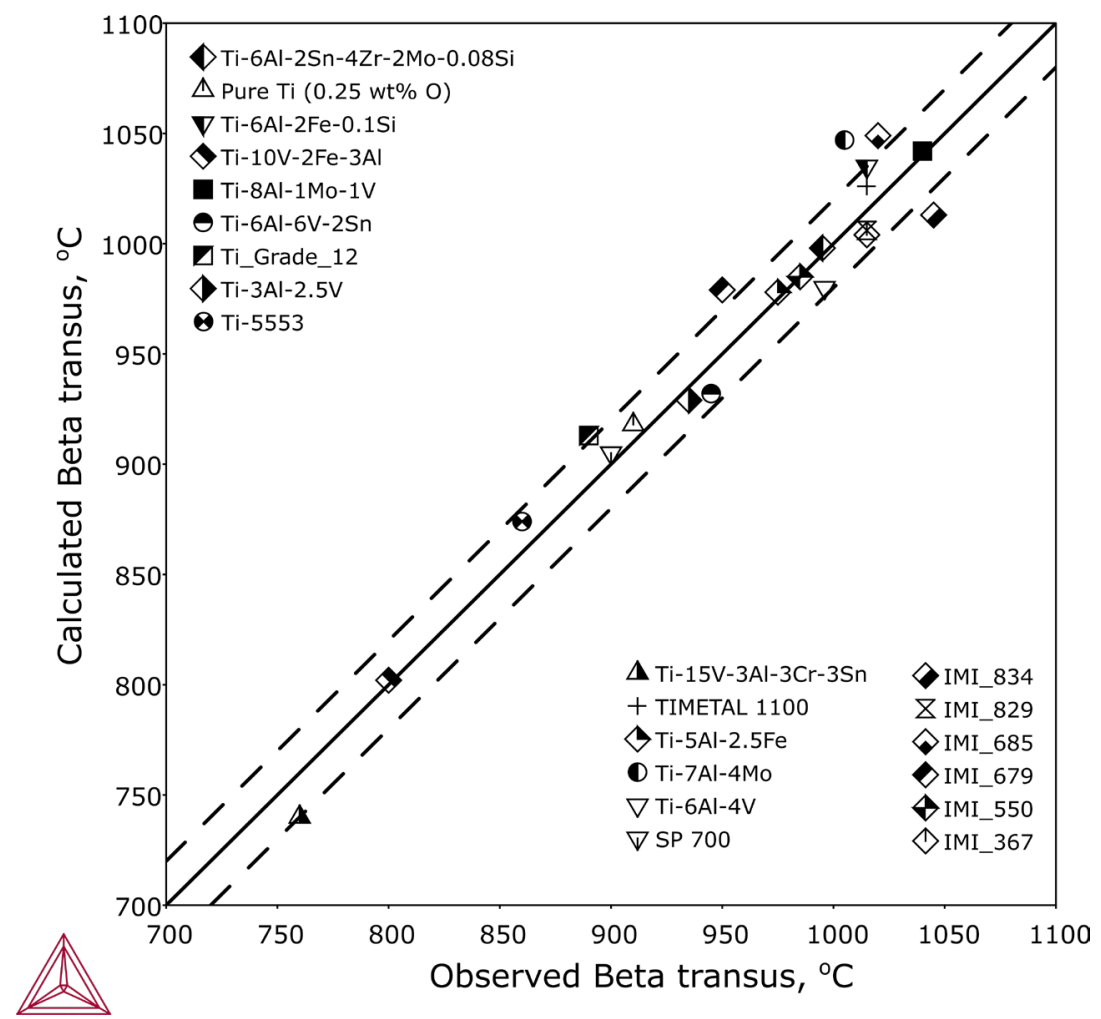


Fig. 3. Comparison between experimentally observed and predicted $\beta$-transus temperatures for Ti-

\section{Alloys.}

\subsection{Martensitic transformations}

Martensitic transformation takes place at the $\mathrm{M}_{\mathrm{S}}$ temperature on quenching a titanium alloy from its $\beta$ phase region to room temperature. The $\alpha^{\prime}$ martensite is modelled as Hcp_A3 on the Ti-rich side. In fast cooled metastable $\beta$ alloys, the precursor of the precipitation is the metastable $\omega$ phase. Unlike the bulk form of stable $\omega$ phase at high pressure, metastable $\omega$ phase precipitates as nanosized particles in the $\beta$ matrix in titanium alloys.

In TCTI2, as-measured temperatures of the martensitic transformations $\beta \mathrm{Ti} / \alpha^{\prime}$ and $\beta \mathrm{Ti} / \omega$ have been used for validating or improving the descriptions of the Bcc_A2, Hcp_A3 and $\omega$ phases in a number of $\mathrm{Ti}-\mathrm{X}\left(\mathrm{X}=\mathrm{Fe}, \mathrm{Mo}, \mathrm{Nb}, \mathrm{Ta}, \mathrm{V}, \mathrm{Al}, \mathrm{Sn}, \mathrm{Zr}\right.$ ) binary systems. In principle, the $\mathrm{T}_{0}$ lines should be compared with averaged temperatures of $A_{s}$ and $M_{S}$ or $A_{f}$ and $M_{f}$. The $T_{0}$ line was directly compared with the experimental data, where we try to keep the line between the starting temperatures and the finishing temperatures. Here is the Ti-V binary system demonstrated as an example. 


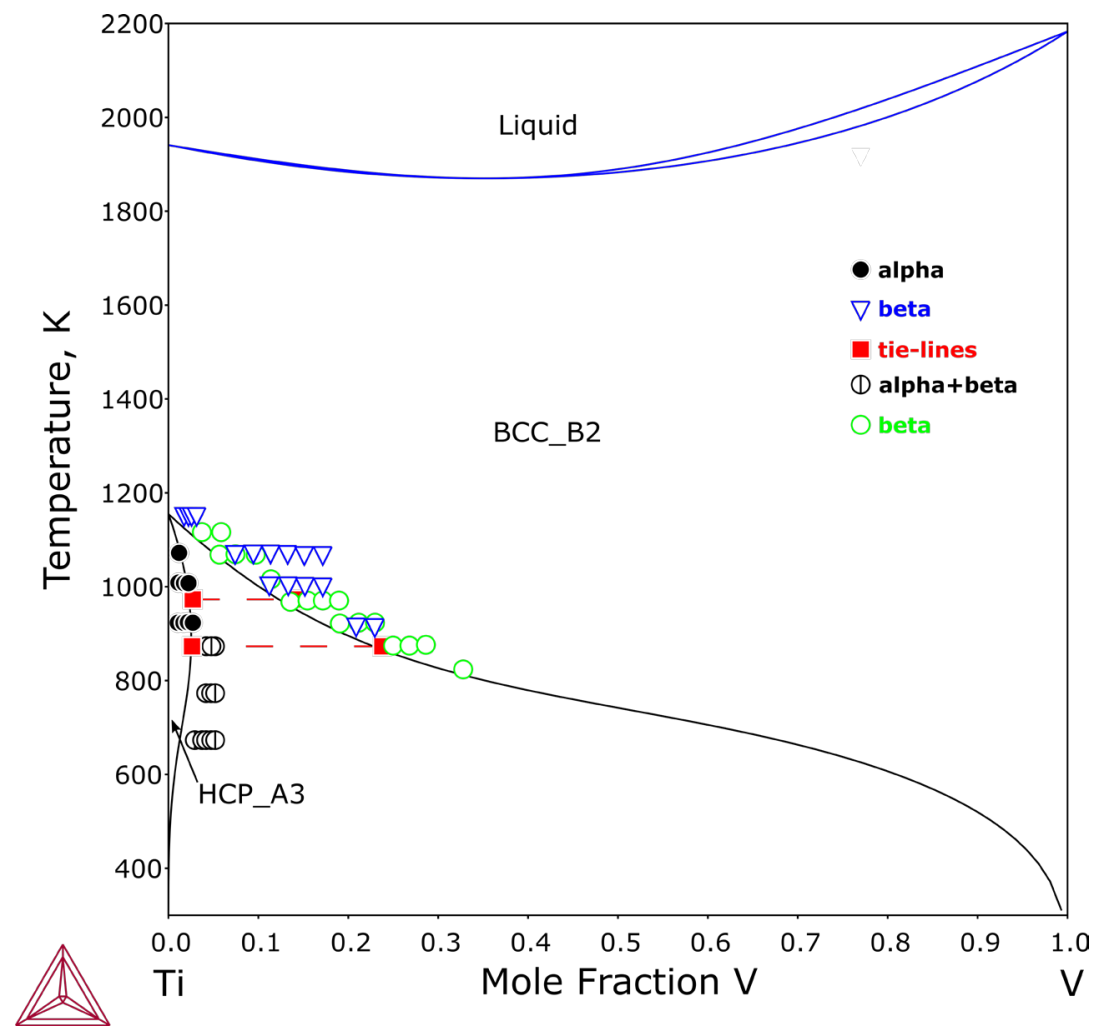

Fig. 4. Calculated Ti-rich Ti-V phase diagram with experimental data from [34-36]. 


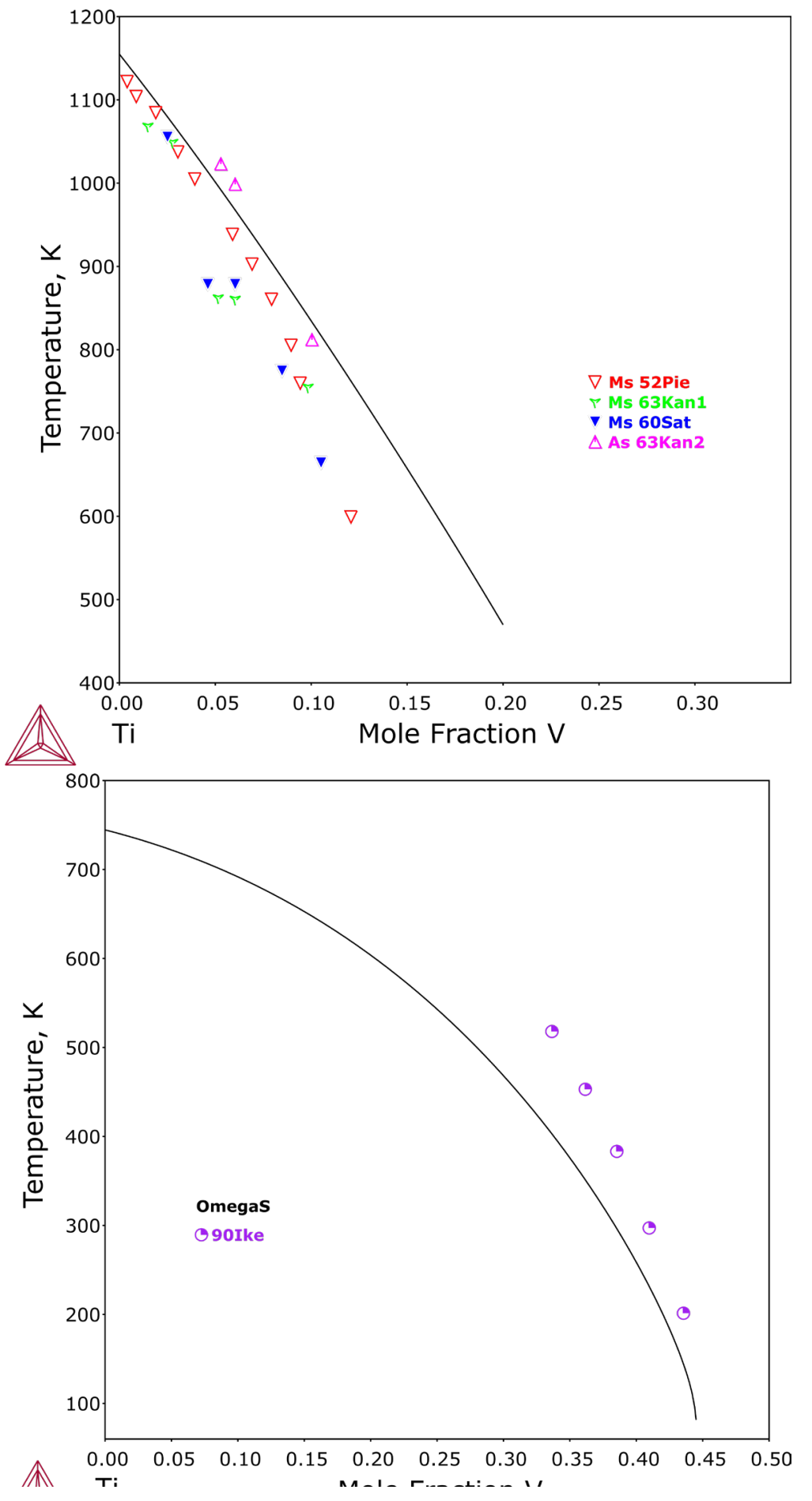




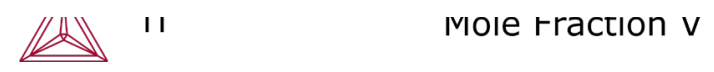

Fig. 5. Calculated Bcc_A2/Hcp_A3 $\mathrm{T}_{0}$ line (a) and Bcc_A2/ $\omega \mathrm{T}_{0}$ line (b) in Ti-V binary system with experimental data from [29-33].

Experimental data of different sources [34-36] have been used in the Ti-V system for determining the Bcc_A2 and Hcp_A3 phase boundaries, as shown in Fig. 4. It's shown in Fig. 5 the Bcc_A2/Hcp_A3 T line fits to the data very well in the Ti-rich region while deviations exist for $\mathrm{V}$ content more than 10 at.\%. It was found in the assessment the $\mathrm{T}_{0}$ data contradict the equilibrium phase diagram data apparently. A compromise was made and the Hcp_A3 description was adjusted to get a better fit to the A2/A3 $\mathrm{T}_{0}$ line and to keep the Hcp_A3 boundary reasonable at the same time. In order to get a better fit to the $\mathrm{A} 2 / \omega \mathrm{T}_{0}$ line, the description of omega $\mathrm{V}$ was adjusted based on DFT calculations.

\subsection{Thermophysical properties}

Technical difficulties exist in casting titanium alloys due to their high melting points, contamination with oxygen and chemical reactions with mould materials. Therefore, solidification simulations are an important complement to experimental means in the optimization of casting processes. Thermophysical properties, such as density, enthalpy $\left(\mathrm{H}_{\mathrm{T}}-\mathrm{H}_{298}\right)$, thermal expansion, etc., are normally required as input for process simulations. Accurate values of thermophysical properties for liquid industrial alloys are particularly essential for high-temperature technologies $[37,38]$ and to improve the simulations of casting and welding. A major achievement of TCTI2 is that such data can be readily calculated for different alloys from room temperature into the liquid state, which is of vital importance for process (casting, welding) simulation but difficult to measure or otherwise estimate.

Fig. 6 shows the linear expansion of Ti- $6 \mathrm{Al}-4 \mathrm{~V}$ up to $1500^{\circ} \mathrm{C}$ compared with experimental results [39-41]. A good prediction can be made even in the region close to the $\beta$-transus where the amounts of $\alpha$ and $\beta$ change rapidly with temperature. 


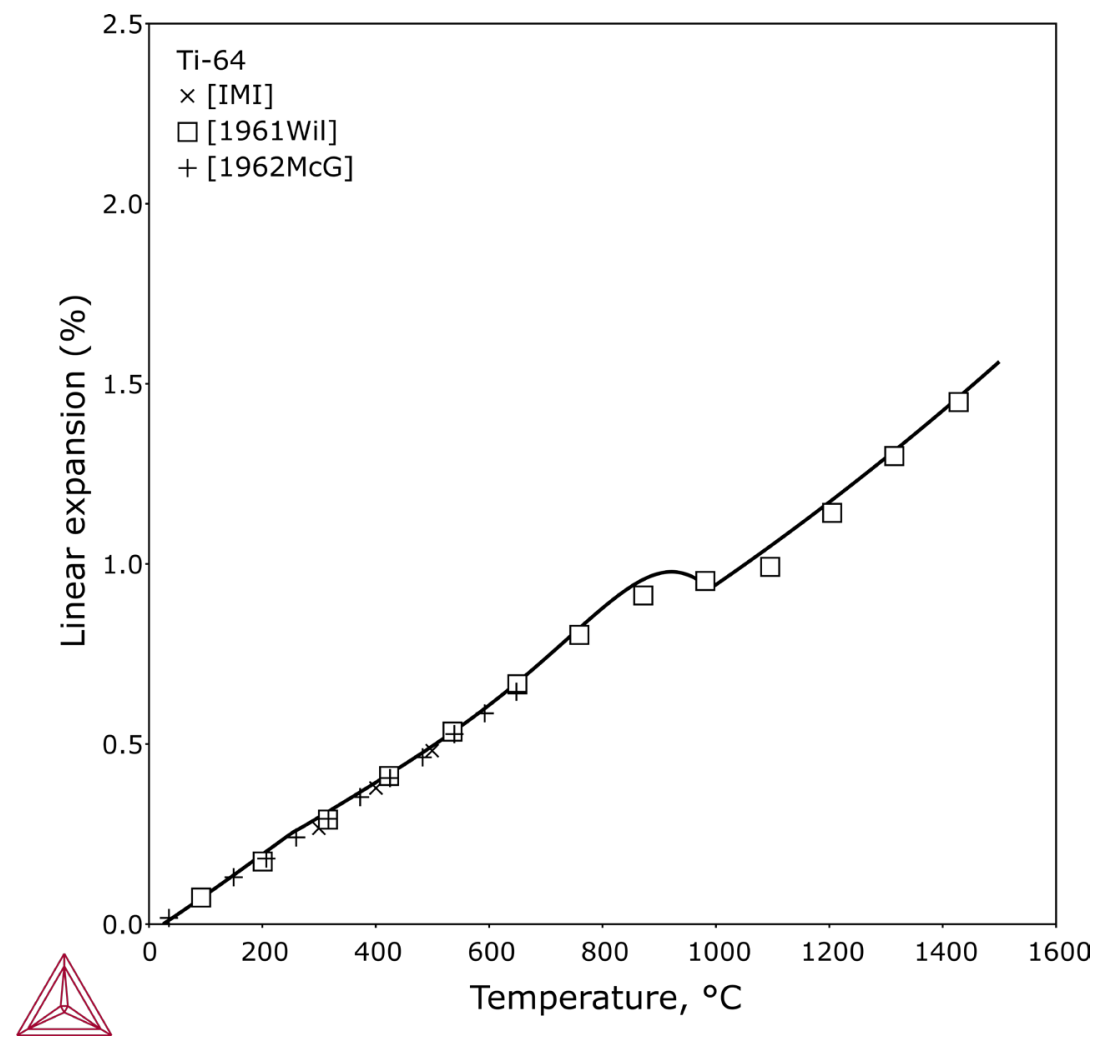

Fig. 6. Linear expansion rate for Ti-6Al-4V.

A key property for process simulation is enthalpy which is needed to model the release of heat during the solidification process. Reliable predictions for enthalpy of Ti-64 in both solid and liquid state are compared with experimental measurements [42] using different techniques, as seen in Fig. 7.

Density is a fundamental material property, which is crucial for casting process and for determining surface tension and viscosity from the measured raw data. Fig. 8 shows the calculated densities of liquid Ti-Al-Nb alloys compared with experimental results [43-44]. 


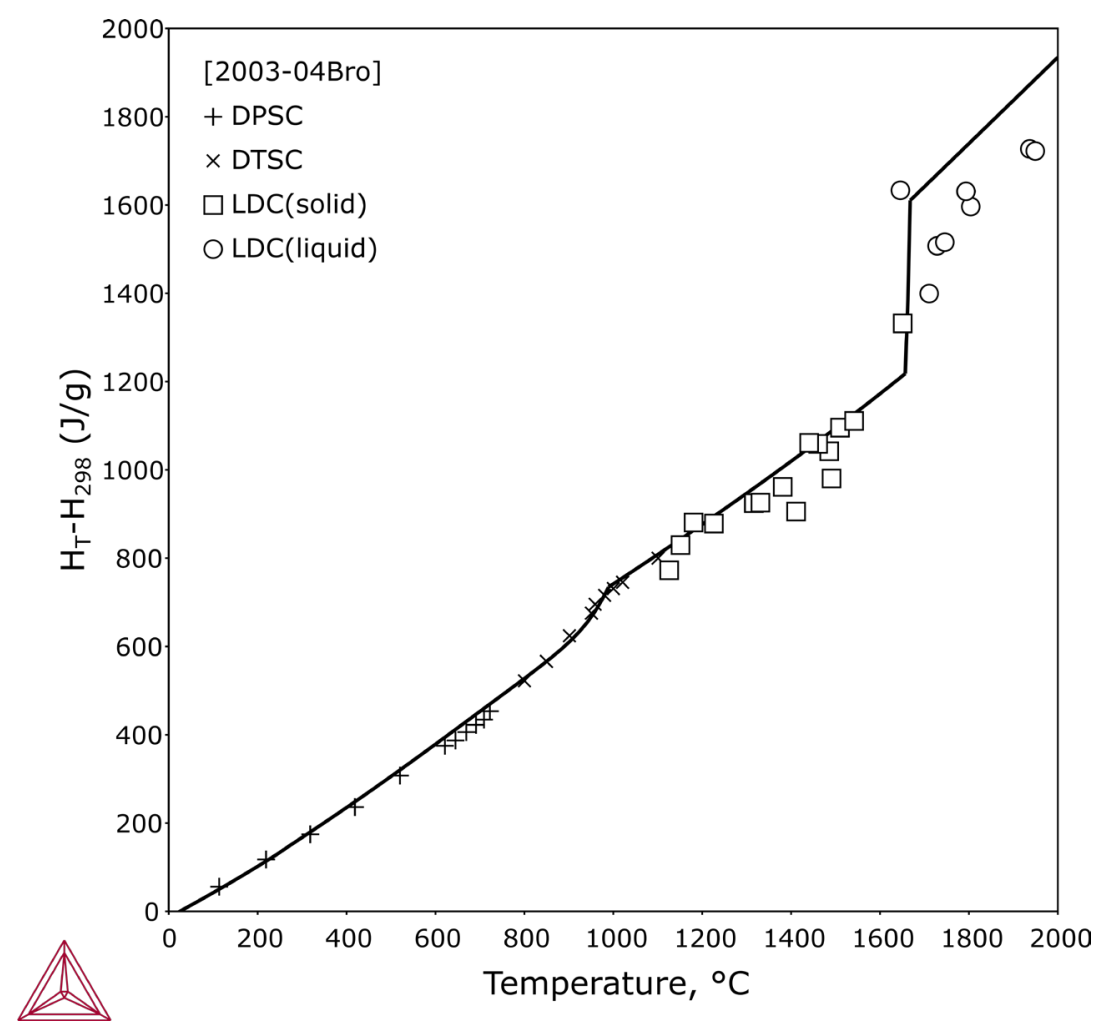

Fig. 7. Comparison between measured and calculated enthalpy of Ti-6Al-4V. 


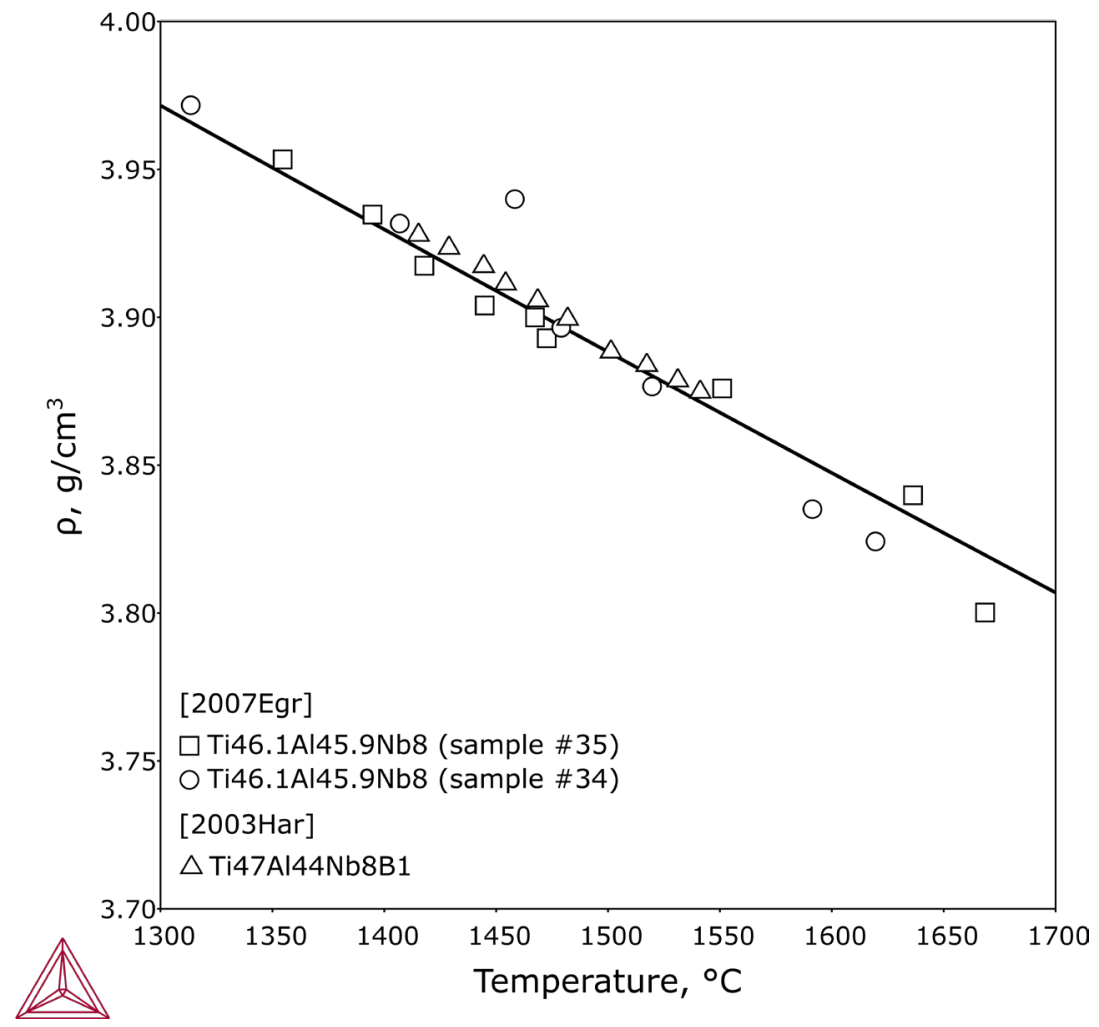

Fig. 8. Density of liquid Ti-Al-Nb.

\section{Conclusions}

The TCTI2 database has been developed for Ti- and TiAl-based alloys within a 27-element framework (Ag-Al-B-C-Co-Cr-Fe-H-Hf-Mn-Mo-N-Nb-Ni-O-Pd-Pt-Re-Ru-Si-Sn-Ta-Ti-V-W-Y-Zr). It has been demonstrated the database can be used to precisely calculate phase equilibria, including phase fractions and compositions, to reliably account for phase transformations with light impurities $\left(\mathrm{O}, \mathrm{N}, \mathrm{H}\right.$, etc.) taken into account, e.g. beta transus temperatures and $\mathrm{T}_{0}$ lines of martensitic transformations, and to faithfully predict some thermophysical quantities in multicomponent commercial alloys. One may couple TCTI2 [16] with the atomic mobility database, MOBTI3 [17], to study diffusion-controlled phenomena, such as solidification, nucleation, 
growth/dissolution and coarsening of precipitates by using the add-on Diffusion Module (DICTRA) or Precipitation module (TC-PRISMA) in the Thermo-Calc software package.

There are several reasons for the difficulty to develop the CALPHAD databases. For example, in $\gamma$ TiAl based alloys the stable phases and the respective amounts vary relatively strongly with composition and temperature. As we know low levels of light element impurities, such as O, C, N, can significantly modify phase equilibria in Ti-based alloys. Even very small variations in composition may drastically change the microstructure. Furthermore, it is difficult to obtain reliable experimental results for Ti-alloys due to problems such as the risk of contamination, specifically from oxygen. With new experimental data which are feasible to resolve conflicts among existing literature data, as well as to close gaps related to missing data, a continuous improvement and development of the TCTI database can be expected. The development of titanium alloys will be undoubtedly advanced by using a reliable CALPHAD computational software and accurate CALPHAD databases, which contributes to a reduction of costly trial and error experiments.

\section{$\underline{\text { References }}$}

[1] G. Lütjering, J. C. Williams, Titanium, Springer, Berlin, 2007.

[2] C. Leyens, M. Peters (ed), Titanium and Titanium Alloys. Fundamentals and Applications, WILEY-VCH, Weinheim, 2003.

[3] M. J. Donachie, Titanium, A Technical Guide, ASM International, Ohio, 2000.

[4] H. Clemens, H. Kestler, Adv. Eng. Mater. 2 (2000) 551-570.

[5] M. Weimer, T. Kelly, Gamma TiAl Applications at GE Aviation, in: Structural Aluminides for Elevated Temperature Applications: Gamma Titanium and Other Metallic Aluminides, New Orleans, USA, (2008) 5-6.

[6] T. Noda, Current Status of Mass Production of Gamma Titanium Aluminide Alloy Turbine Rotors in Turbochargers and Future Challenges, in: Structural Aluminides for Elevated Temperature Applications: Gamma Titanium and Other Metallic Aluminides, New Orleans, USA, (2008) 7-8. 
[7] H. Clemens, W. Smarsly, V. Güther, S. Mayer, Advanced intermetallic titanium aluminides, $13^{\text {th }}$ World Titanium Conference Proceeding, San Diego, USA, (2015) 1189-1200.

[8] Y. L. Hao, R. Yang, Y. Y. Cui, D. Li, Acta Mater. 48 (2000) 1313-1324.

[9] R. Kainuma, Y. Fujita, H. Mitsui, K. Ishida, Intermetallics 8 (2000) 855-867.

[10] U. R. Kattner, JOM 49 (1997) 14-19.

[11] H. L. Lukas, S. G. Fries, B. Sundman, Computational Thermodynamics: The Calphad Method, Cambridge University Press, New York, 2007.

[12] N. Saunders, A.P. Miodownik, Calphad - Calculation of Phase Diagrams: A Comprehensive Guide, Pergamon Press, Oxford, 1998.

[13] B. Sundman, Thermo-Calc, A General Tool for Phase Diagram Calculations, in: M. Doyama, T. Suzuki, J. Kihara, R. Yamamoto (Eds.), Computer Aided Innovation of New Materials, North Holland, Amsterdam, 1991.

[14] J. O. Andersson, T. Helander, L. Höglund, P. F. Shi, B. Sundman, CALPHAD 26 (2002) 273-312.

[15] Thermo-Calc Software, The Precipitation Module (TC-PRISMA) User Guide (accessed December 2018)

[16] Thermo-Calc Software, TCTI Ti-based Alloys database version 2 (released December 2018)

[17] Thermo-Calc Software, MOBTI Ti-alloys Mobility Database version 3 (released December 2018)

[18] X.-G. Lu, M. Selleby, B. Sundman, Acta Mater. 53 (2005) 2259-2272.

[19] X.-G. Lu, M. Selleby, B. Sundman, Calphad 29 (2005) 68-89.

[20] SGTE Pure Element Database, SGTE, Scientific Group Thermodata Europe, 2009, Version 5.0. 
[21] J.-W. Yeh, S.-K. Chen, S.-J. Lin, J.-Y. Gan, T.-S. Chin, T.-T. Shun, C.-H. Tsau, S.-Y. Chang, Adv. Eng. Mater. 6 (2004) 299-303.

[22] I. Ansara, N. Dupin, H. L. Lukas, B. Sundman, J. Alloys Compd. 247 (1997) 20-30.

[23] N. Dupin, I. Ansara, B. Sundman, CALPHAD 25 (2001) 279-298.

[24] J. Ågren, ISIJ International 32 (1992) 291-296.

[25] W. J. Boettinger, U. R. Kattner, S. R. Coriell, Y. A. Chang, Development of multicomponent solidification micromodels using a thermodynamic phase diagram data base, in : Modeling of casting, welding and Advanced solidification Processes, VII, TMS, Warrendale, PA, (1995) 649-656.

[26] P. Erdely, R. Werner, E. Schwaighofer, H. Clemens, S. Mayer, Intermetallics 57 (2015) 17-24.

[27] R. Boyer, E. W. Collings, G. Welsch, Materials Properties Handbook: Titanium Alloys, ASM International, 1994.

[28] S. L. Semiatin, T. M. Lehner, J. D. Miller, R. D. Doherty, D. U. Furrer, Metall. Mater. Trans. A, 38 (2007) 910-921.

[29] P. Pietrokowsky, P. Duwez, Am. Inst. Min. Metall. Pet. Eng. Soc. Min. Eng. AIME, 194 (1952) 627630.

[30] H. Kaneko, Y. C. Huang, J. Jpn. Inst. Met., 27 (1963) 387.

[31] T. Sato, S. Hukai, Y. C. Huang, Journal of the Australian Institute of Metals, 5 (1960) 149.

[32] H. Kaneko, Y. C. Huang, J. Jpn. Inst. Met., 27 (1963) 403.

[33] M. Ikeda, S. Y. Komatsu, T. Sugimoto, K. Kamei, J. Jpn. Inst. Met., 54 (1990) 743-751.

[34] H. K. Adenstedt, J. R. Pequignot, J. M. Raymer, Trans. Metall. Soc. AIME., 44 (1952) 990-1003.

[35] V. V. Molokanov, D. B. Chernov, P. B. Budberg, Met. Sci. Heat Treat., 19 (1977) 704-705. 
[36] F. Ermanis, P. A. Farrar, H. Margolin, Trans. Metall. Soc. AIME, 221 (1961) 904-908.

[37] H. J. Fecht, R. K. Wunderlich, Proc. First Int. Symp. on Microgravity Research \& Applications in Phys. Sci. \& Biotechnol., Sorrento, Italy, 10-15 September 2000 (ESA SP-454, January, 2001), 545552.

[38] A. Ludwig, Int. J. Thermophys. 23 (2002) 1131-1146.

[39] IMI Titanium property data, report MK140/589.

[40] D. N. Williams, Trans. Met. Soc. AIME, 221 (1961) 411.

[41] W. M. McGee, B. R. Matthews, U. S. A. F. Rept. ASD-TDR-62-335 (2A), 1962.

[42] R. F. Brooks, J. A. J. Robinson, L. A. Chapman, M. J. Richardson, High Temperatures-High Pressures, 35-36 (2003-2004) 193-198.

[43] I. Egry, R. Brooks, D. Holland-Moritz, R. Novakovic, T. Matsushita, E. Ricci, S. Seetharaman, R. Wunderlich, D. Jarvis, Int. J. Thermophys. 28 (2007) 1026-1036.

[44] R. Harding, R. Brooks, G. Pottlacher, J. Brillo, Thermo-physical properties of a Ti-44Al-8Nb-1B alloy in the solid and molten conditions, in: Gamma Titanium and Other Metallic Aluminides, TMS, Warrendale, PA, (2003) 75-82. 